\title{
Politeness and Indirectness in Donald Trump's Intercommunication
}

\author{
Rauf Kareem Mahmood ${ }^{1,2}$, Hezha Muhammad Rasheed ${ }^{2}$ \\ ${ }^{1}$ Department of English, College of Languages, University of Slemani, Sulaymaniyah, Kurdistan Region, Iraq \\ 2 Department of English, College of Languages, University of Human Development, Sulaymaniyah, Kurdistan Region, Iraq
}

\begin{abstract}
This paper elaborates the notion of politeness as a pragmatic concept and attempts to find answers regarding the strategies followed to achieve a polite act within a course of communication. Both the speaker and the hearer tend to act politely (in accordance to their beliefs regarding a polite act) and expect to be treated alike. However, the type of politeness considered in this paper is different from that of a culture-based concept.

Pragmatic Politeness consists of following a number of principles and maxims in accordance to a particular context. Both types of the concepts are connected to the notion of 'face' which refers to the image that both the speaker and hearer desire to save, whenever they are intercommunicating. The face saving of interlocutors requires the adaptation of Leech's Politeness principle and maxims. This paper examines both 'direct' and 'indirect' strategies to approach politeness in Donald Trump's political intercommunications verify or nullify common claims that politeness is achieved throughout indirect methods. The paper hypothesizes that both strategies are applicable to fulfill a communicative polite behavior on the basis of proper context..
\end{abstract}

Index Terms - Pragmatics, Politeness, Speech Acts, Indirectness, Donald Trump.

\section{INTRODUCTION}

The notion of Politeness has two different dimensions; the commonly known is the cultural/social one, while the less noticed is the scientific/pragmatic one. This research paper sheds light on the latter with reference to Leech's politeness principle (1983). It is a matter of confusion though, to differentiate between the scientific and cultural politeness since their goals are similar and the strategies are somehow alike. The paper isan effort to provide sufficient answers to the question regarding the strategies adapted to obtain politeness in communication. The paper highlights indirectness as the mostly agreed upon approach to politeness, and tries to prove whether or not such a claim is reliable with the evidence of 12 randomly selected samples from the intercommunication between Donald J. Trump, the former US president and the press.
The adaptation of politeness strategies varies by virtue of culture, power, weight of the imposition, social distance, age, sex, intimacy, group membership, and kinship. Such strategies are not interpreted equally across cultural and ethnic boundaries.

The different application of those strategies sometimes cause problems among the speakers of one language and/or others of a second language, since misunderstanding occurs often among speakers of one language and the same is expected to happen for those who do not share the same cultural and social background, because the politeness strategies of the speaker's mother tongue may differ from the second or primary language that he/she acquires. For example, one of the questions to be asked is: Does the culture defer to the addressee's desires and opinions in a direct manner? In America, the answer is "yes." If a guest refuses the offer of more food, for instance, his/her refusal is accepted at face value and the offer is not repeated. In Poland and India, however, the guest would be encouraged to eat some more and the host will practically insist that $\mathrm{s} / \mathrm{he}$ does so. It does not mean that the Polish and Indian cultures do not defer to the wishes of the guests; it simply means that a refusal of an offer for food or drink is not to be accepted readily. (Kachru and Smith 2008, p.49) (LoCastro 2012, p.142)

\section{COMMUNICATION AND POLITICAL DISCOURSE}

Communication is a social behavior in which two or more individuals get to exchange ideas, thoughts, and express feelings and emotions. Technically, the process is encoding a message by the speaker and, decoding it by the hearer throughout a cognitive system. A successful communication is due to the assumption of a shared background knowledge concerning the discussed topic between the communicators, i.e., the communicators tend to have harmony assuming that the communication runs in accordance to specific form and regulation. This assumption comes to an end until it proves the

Journal of University of Human Development

Volume 7 No. 3(2021); DOI: 10.21928/juhd.v7n3y2021.pp13-24

Regular research paper: Received 7 March 2021; Accepted 28 March 2021; Published 4 July 2021

Corresponding author's e-mail: rauf.mahmood@univsul.edu.iq, hezha.rashid@uhd.edu.iq

Copyright (c) 2021 Rauf Kareem Mahmood, Hezha Muhammad Rasheed. Author's Names. This is an open access article distributed under the

Creative Commons Attribution License (CC BY-NC-ND 4.0) 
contrary in case of misunderstanding or misleading.

The first assumption two interlocutors have when communicating is to have their face protected from being threatened in terms of protecting their public image. Due to its internationality, where most speakers of different languages around the world are aware of, indirectness is the common choice they make when the speakers prefer to deliver an unsolicited note to the listeners in the shape of an implicature. The implicature is often interpreted by the hearer by forming an inference.

Other different factors urging the employment of indirect speech acts in communication would be vocabulary insufficiency, performance error, avoiding the embarrassing and taboo topics, in addition to temporary psychological states of the speaker, such as stress, nervousness, fear and excitement. However, the indirectness of this type is apparently, unintentional.

Aiming at obtaining social and communicative advantages, for instance, speaker's wish for his/her language to be fascinating, desire to increase the force of the message, and competing goals are the primary possibilities for the speaker's choice of being indirect. Individuals utilize their power, social distance and the concept of right and obligation in the community to imply indirectness. Nevertheless, the main reason triggering indirectness is politeness.

According to (Cook 2003, p.61), political discourse is great and the greater the discourse, the greater the scope for disagreement. This greatness is due to the subtle ways of using language to influence and mislead. This disagreement is intriguing. Accordingly, there is a need to understand and combat such language uses, a need to uncover their interwoven texture and rhetorical strategies, augmentative appeals, and other augmentative tactics. These crafted strategies seek to captivate our contemplation, win our patronage, and change our demeanor. (Cited in the Pragmatics of Cogent Argumentation in British and American Political Debates Al-Juwaid 2019, p.45)

In a prime ministerial or presidential context, an argument is a way of enacting character, of demonstrating the ability to lead, and because political debates call for arguments, they are opportunities to enact a prime ministerial or a presidential image (Hinck 1993, p. 6). By responding to the substantive demands of a question or an opposing argument, a candidate shows that he or she has the intelligence to argue to defend his or her image, i.e. a candidate demonstrates an ability to defend against symbolic attacks. Worded differently, such context includes disputes that need to be resolved. As the language used in such a context is highly institutionalized in the sense that it is well crafted not only to attract the attention of the audience but also to convince them of the standpoints presented, this study scrutinizes what makes such a language cogent. Moreover, prime ministerial or presidential debates, as an example of highly eristic context, among others, present a picturesque example where all these issues can be applied. (ibid. p.46).

\section{PRAGMATICS}

Pragmatics was first introduced as an independent field of Linguistics, in (1938) by Charles W. Morris. He addressed it as:

\begin{abstract}
"The signs of the relations of signs to their interpreters. [...] since most, if not all, signs have as their interpreters living organisms, it is a sufficiently accurate characterization of Pragmatics to say that it deals with the biotic aspects of semiosis, that is, with all the psychological, biological and sociological phenomena which occur in the functioning of signs." (1938, cited in Verschueren 1999, p.6)
\end{abstract}

Yule (1996, p.3) suggests four areas that he believes pragmatics is concerned with. The first is the "study of speaker's meaning". This suggests that pragmatics is about analyzing what the speakers mean by their utterances rather than the meaning of words and phrases alone. The second domain of pragmatic interest for Yule is studying "contextual meaning", i.e., the speaker's arrangement of his/her utterances in regards to whom, where, when and under which circumstances does the communication take place. The study of how more is communicated than what is literally stated is the third field of pragmatic study, according to Yule. He suggests that pragmatics is the study of invisible meaning in terms of exploring what is unsaid through inference formation by the hearer. Finally, Yule links the speaker's choice to the notion of distance. He proposes that social, physical, and conceptual closeness effects the expressions collaborated by the speaker, due to the shared experiences, i.e, the distance between the two parties imposes on the speaker the amount of data he/she desires to mention.

Disputing the thought that pragmatics is not an addition to Linguistic Theory, Verschueren (1999, pp. 6-7) suggests a different perspective. He believes that, the absence of a notable component to be analyzed upon and/or, any inadequacy to interdisciplinary fields of linguistics due to the lack of a linking object to which language is studied does not make Pragmatics any less dominant field of Linguistics. (Phonetics, Phonology, Morphology, Syntax and Semantics) for instance, each has its own unit to be analyzed upon such as; (phones, phonemes, morphemes...) respectively. The same is for the interdisciplinary fields of Linguistics such as; (Sociolinguistics, Psycholinguistics, and Neurolinguistics) where they each have an object linking them to language studies, where each one is concerned with the study of language and (Society, Psychology and the brain) respectively. However, for Yule Pragmatics is concerned with a full complexity of linguistic behavior in terms of society, culture and cognition. Therefore, he defines it in terms of them all as "a general cognitive, social and cultural perspective on linguistic phenomena in relation to their usage in forms of behavior."

In addition to defining Pragmatics as one component of human language study and a branch of linguistics, Chapman (2011, p.1) consents to Verschueren's belief and studies the field from a multi-dimensional concept. He points out, 
"concepts, theories and approaches developed within Pragmatics, are being used by those working in many other areas: both in other branches of linguistics, such as sociolinguistics, stylistics and psycholinguistics, and in different disciplines, such as artificial intelligence, clinical psychology and even Law."

Furthermore, he explains Pragmatics in three terms. An 'informal term', that is, what people mean rather than what they say. Then, 'more precise definition' regarding Pragmatics as meaning in use rather than that of literal meaning. Finally, a technical meaning that concerns studying meaning minus truth condition.

The notion of viewing Pragmatics from the language user's perspective is shared between Crystal (2003, p.364) and LoCastro (2012, p.39). Crystal suggests that, in modern linguistics, pragmatics has to be applied to the study of language from the user's point of view. The linguistic choices the speaker makes in social interactions, and the impact those choices have on other communicators, must be considered. LoCastro, however, believes that, despite being a cognitive process, pragmatics is a social and cultural perspective of linguistic phenomena in relation to their usage in the form of behavior. As a result, through the inference-formation process, the listener infers the speaker's intended meaning, which leads to the assumption that Pragmatics is essentially the study of the extra meaning or that type of implied meaning which has not been explicitly stated in the utterance i.e. it is the study of whatever the speaker has in his mind and wishes to convey.

Emphasizing the significance of Pragmatics in Linguistics, Taguchi (2019, p.1) discusses the role of Pragmatics in second language learning. She highlights the fact that learning a second language is not restricted to its grammar and vocabulary but the appropriateness of manifesting one's ideas and intentions in a way that fits the current circumstances and cooperates with the situation, plays a great part of becoming a competent second language speaker.

Although Levinson (1983, pp.7-9) suggested his preference to limit Pragmatics definition to principles of language usage only in terms of performance, without any reference to linguistic structures, but realizing the fact that the term pragmatics covers both context-dependent aspects of language structure and principles of language usage, he then offered the following definition: "the term pragmatics covers both contextdependent aspects of language structure and principles of language usage". Additionally, Mahmood (2016: p. 128) points out: "A quick look is enough to observe that context, as the main tool or unit of studying pragmatics, goes more smoothly with culture, mind, brain, etc., and not with phoneme, morpheme and sentence." Due to the fact that, both "Pragmatics" and "Semantics" deal with meaning, misconceptions might happen regarding their absolute boundaries. Leech (1983, p.15) has suggested a clear distinction between both fields. To him, Pragmatics, unlike semantics, is concerned with meaning in relation to a speech situation, whereas speech situation consists of addresser and addressee, context, goal, illocutionary act and utterance.
In his 1983 Principles of Pragmatics book, Leech has made it clear that he focuses on the type of pragmatics that studies linguistic communication in terms of conversational principles which have a rhetorical model. That is, effective use of language in its most general sense into everyday communication and only secondarily to the more prepared and public uses of language. He also refers to the significance of considering both pragmaliguistics that is language specific studies and Sociopragmatic that is culture-based studies in communication.

To sum it up, pragmatics answers why a particular behavior is adopted in particular circumstances. It interrogates the communicators' ability of figuring out how to run a successful conversation cooperatively and smoothly, and attempting to find alternative meanings in case of having gaps in communication, until they reach a desired outcome of the conversation. It also studies the strategies used by interlocutors to run a successful conversation.

\section{SPEECH ACT THEORY}

The notion of speech act entails the fact that, through speaking, a person accomplishes goals. Speakers choose ways to express themselves, aiming at making the listeners fully understand their intention to believe, accept or do what they speak. (Bonvillain1993, p.101)

According to Verschueren (1999, p.22), speech acts form one of the basic ingredients of pragmatics. It was first introduced by John Austin as a reaction to the "Logical positivism" movement that Austin calls "Descriptive Fallacy" (Chapman 2011, p.57). According to logical positivism, the only truthful meaning of language is that of logical analysis, in terms of truth and falsity, whereas Austin verified his theory by dividing utterances according to their function to label what is said, as "Constative" and what is done, as "Performative" in uttering specific thoughts.

Chapman (2011, pp.56_57) treats speech acts as a part of "Classical Pragmatics" for two reasons; being classical in the sense of founding and originality, and representing the establishment within the discipline by means of setting the standards for the type of explanation, the framework for analysis and in many cases the actual terminology used in pragmatics. What he tries to imply is that the concept has not changed ever since it was first released. Austin modified the theory several times, aiming at improving his insights, as well as some terminologies that he thought are of no more of use. This could be evidence that the "speech act theory" is a dynamic theory.

Austin uses the term "speech act" to refer to "an utterance and the total situation in which the utterance is issued". In the present time, the term is used to mean the same as "illocutionary act" which is essentially considered the focal point of the speech act theory itself (Thomas 2013, p.51). Austin also mentions the possibility of a solo speech act performing multiple meanings just as it is the case for one word to express different speech acts, such as, "He has been acting so funny". Taking into 
consideration different contexts, this sentence might imply that the person was simply funny, or he was acting in a strange way (in terms of his ordinary personality), or he hasn't been normal (he appears to suffer health issues). The following illustrates the idea of different expressions performing one speech act for example where all the utterances imply the request of 'close the door';

(1) Shut the door.

Could you shut the door?

Did you forget the door?

Put the wood in the hole!

Where you born in a barn?

What do big boys do when they come into a room? (Thomas 2013, p.51)

Despite the fact that each of these terms "speech act, illocutionary act, illocutionary force, pragmatic force" may imply different theoretical positions, however, they are all used to mean the same thing (ibid.).

\section{A. Direct Speech Act}

According to Yule (1996, pp.54-55), a direct speech act is whenever a clear and direct relationship between the form and the function exists in a sentence. i.e., when a declarative sentence is intended to be informative (statement) for instance. This means that the speaker has no intention to generate a complicated message.

Crystal (2003, p.140), on the other hand, highlights the speaker's purpose in uttering the statement by means of getting someone (usually the hearer) to do something for the speaker. Black (2006: p.19) calls it a direct correlation between the grammatical form of an utterance and its illocutionary force, i.e. when there is a direct mapping between form and function of the utterance.

(2)The world is his stage. (Declarative, performing informative)

\section{B. Indirect Speech Act}

Indirect speech act refers to the types of utterances where the relationship between the form and function of the statement is indirect. i.e. no clear link exists between what is said and what is meant. It is the type of speech act where the speaker leaves the hearer to work out the meaning s/he intends. (Black 2006, p.19)

This is often a simple task for the addressee to accomplish, by interpreting the meaning (the force of the utteranceillocutionary act) via inference. (Dawn \& Wichmann 2012, p.41). The inference is based on shared knowledge between the communicators.

The most common type of indirect speech act for Yule (1996, p.56), however, is that of a request form. He believes that such utterances have a demand for an action despite their direct appeal for an answer, as in:
(3) Can you hand me the pen?

The speaker is basically asking the hearer to perform an action rather than asking about showing him/her certain physical capability. The speaker is seemingly considering the fact that despite the hearer's capability to do the act, s/he might refuse to perform it or is not simply interested in doing it for any possible reason. Therefore, the speaker seeks his/her request in a way to effectuate the hearer in addition to avoiding any embarrassment to him/her. So, it can be stated that the speaker respects the hearer's freedom of action and tends to show solidarity, not imposition.

Yule (1996, p.56) believes that to be polite is to be indirect in expressing yourself. That might be the case but only if we take a look at the context to understand why.

According to Saeed (2009, p.247), individuals in a set of conversational participants are required to maintain a kind of mutual self-interest that is maintaining self and other interactor's face. This claim harms both faces of the interlocutors, since many verbal interactions appear as threats. For example, advising, suggesting, requesting and ordering are threats to other's negative face, for the other's freedom of choice or autonomy has been violated. Then, to disapprove, disagree, accuse and interrupt, threat, curse, causes harm to the positive face, since the self-image has been destroyed. Again, confessions and apologies make pose a threat to one's own face.

Therefore, to Saeed (2009), indirect speech acts are among a series of strategies that individuals tend to use in an attempt to reduce the threats to both faces. For example, to request in an indirect pattern, 'Would you please turn off the TV?' instead of a direct request 'Turn off the TV.' that Saeed refers to it as 'negative politeness' since it lessens the weight of a request on the hearer's face, whereas a positive politeness pattern reduces the threat in a disagreement, interruption or disapproval, such as; 'I am afraid to say that you are wrong' instead of a direct state 'You are wrong'.(ibid p. 247)

So, most people believe that the more indirect the utterance is, the politer it would be, as Leech (1983, p.108) states, the indirect statements tend to be politer because they increase optionality for the hearer, whilst decreasing illocutionary force.

However, some criticize Leech for ignoring the fact that indirectness can even be impolite. Therefore, context plays an important role in the illustration of politeness. Just like his contribution to sarcasm and banter, a contribution that has been of particular use in the realms of impoliteness. He first defined them in terms of irony as follows: 'If you must cause offence, at least do so in a way which doesn't overtly conflict with the PP, but allows the hearer to arrive at the offensive point of your remark indirectly, by way of an implicature'. He later expands: Apparently, then, the IP is dysfunctional: if the PP promotes a bias towards comity rather than conflict in social relations, the IP, by enabling us to bypass politeness, promotes the 'antisocial' use of language. We are ironic at someone's expense, scoring off others by politeness that is obviously insincere, as a substitute for impoliteness. (ibid, pp.82, 142)

Both concepts of 'politeness' and 'indirectness' will be analyzed in Trump's intercommunication with the press, from 
a pragmatic standpoint, banning the social and cultural view.

Based on Leech (1983, p.104)'s assumption that different kinds and degrees of politeness are called for in different situations, the illocutionary forces are classified into four types, in terms of their relation to social goals in gaining comity. One may argue that, why would it be necessary to mention the social dimension since the subject is covering the pragmatic perception of the concept. It is simply because pragmatics is all about context of communication which is a social behavior of its own. One cannot tell whether the concept is successfully applied, if it is not for the communication context.

1. Competitive: when the illocutionary and social goals compete. In cases of ordering, asking, demanding, and begging.

2. Convivial: when the illocutionary and social goals coincide. For example, inviting, greeting, thanking, and congratulating.

3. Collaborative: the illocutionary and social goals are moderate. Such as asserting, reporting, announcing and, instructing.

4. Conflictive: as the name suggests, both illocutionary and social goals conflict. Namely threatening, accusing, cursing and reprimanding. (ibid)

\section{TRUMP'S MANIFESTATION OF POLITENESS AND INDIRECTNESS IN HIS INTERCOMMUNICATION}

\section{A. Donald J. Trump}

Trump is the 45th President of the United States, who defines the American success story. A graduate from University of Pennsylvania's Wharton School of Finance, following his father's footsteps in the world of business. Trump had also attempts to become an author as he has written more than fourteen bestsellers, including, "The Art of the Deal", the first published book of him and it was considered a business classic. (https://www.whitehouse.gov/people/donald-j-trump/)

Despite his success as a business man, he would approve on setting his foot into the political domain. He eventually managed to take part in the United States' 2016 election campaign as an independent figure whom some referred to as "disruptor" and "outsider" who took advantage of the cozy status of the government that serves allies not the messes (Herbert, McCrisken and Wroe: 2019). (https://www.whitehouse.gov/people/donald-j-trump/)

Similar to any public figure in the society, Trump has got his own share of nation's opinion split about him. For some, he was excused and minded in any act he was involved in while, for others who had an anti-Trump attitude against him, he was obviously not satisfactory at any account.

So, for Gingrich (2017), the American historian and a close friend of Trump family, it was astonishing that the elite media and much of the political establishment refuse to try to understand Donald Trump. According to Gingrich, Trump is one of the most remarkable individuals to ever occupy the
White House and his set of practical business experiences - and his lack of traditional political-governmental experiences-has made him a unique president not the otherwise. In addition to that, Trump is the first person to be elected president without first having served in public office or as a general in the military.

Since he announced his bid for the presidency, Donald Trump has been misunderstood, underestimated, and misrepresented, Gingrich (2017) claims. And having known this himself, Trump acted accordingly. He was well aware of the fact that he was an outsider for the presidency campaign, since he came forwards into the presidency campaign independently with neither support from neither political party nor having any political background himself.

Therefore, he has chosen to abandon all forms of ready speeches and to talk with the crowd spontaneously, where the pundits accused him of "rambling". Yet, it was an act of extraordinary message discipline according to Gingrich (2017). Another change that he initiated was that of self-financing his campaign as many thought that the candidates for the presidency were only listening to the voices of whom they owe their campaign. So, he intended to prove that he is people's president and will serve them all equally.

In the light of the probability that the political establishment and the mainstream media, as Gingrich mentions, are working on representing Trump in a negative way for no specific clear reason so, (Gingrich 2017) instead, advices anyone who wants to know the real Trump, must study his background and neglect everything that comes from those mentioned previously.

Due to his wide experience in business management and decision making and complete conscious of what he has got himself involved in Gingrich (2017) argues that Trump came to take charge of a nation prepared with needed equipment to face any unexpected situation. As he is the man of tough times and he has been to such circumstances in one way or another, himself.

He is also a professional speaker who used to give speeches to gatherings of over 10 thousand people regularly, and this feature of him has served him in being unique in holding fruitful communication with his people where everyone can feel that he is talking to them each and everyone solely with total attention and consideration. (ibid)

In his illustration, Leech had suggested a set of six maxims to determine a polite act in a course of communication. He also addressed them to be as a completion or addition and even rescuer to Grice's (1975) Cooperative Principle, by means of that the Cooperative Principle would be weakened if its apparent exceptions are not satisfactorily explained.

It is worth to mention that different societies view the strategies to a polite act differently. Therefore, the application of the Cooperative Principle might take the priority for some of them, whereas others give the Politeness Principles more credit over the $\mathrm{CP}$ and, eventually sacrifice one of the $\mathrm{CP}$ maxims for the sake of reaching a polite goal. This usually happens in an act of 'irony'

The following examples are illustrations of Donald Trump's manifestation of strategies for a polite act in different occasions. 


\section{A. Tact and Generosity Maxim}

1. In one of the debates in 2016 between Donald Trump and Hillary Clinton, the Democrat candidate for the United States presidential election, a reporter asked both candidates to say something nice about each other since in most of their debates, they were verbally attacking each other. Trump's reply came as the following:

"I consider her statement about my children to be a very nice compliment. I don't know if it was meant to be a compliment, but it is great. I'm very proud of my children, and they've done a wonderful job and they've been wonderful, wonderful kids. So I consider that a compliment.' I will say this about Hillary: 'She doesn't quit, she doesn't give up, I respect that. I tell it like it is. She's a fighter. I disagree with much of what she's fighting for, I do disagree with her judgment in many cases, but she does fight hard and she doesn't quit and she doesn't give up."

https://www.vanityfair.com/video/watch/hillary-clinton-and-donald-trump$\underline{\text { say-something-nice-about-each-other }}$

In the beginning of his speech, Trump observes both Tact and Generosity maxims. The reason for mentioning both maxims together is that following one maxim leads to following of the other accordingly. Therefore, Trump is being tactful and generous giving credit to Hillary's statement where she describes his children. Even though he expresses his hesitation to consider the statement a compliment, however, he soon repeats his gratitude for such an act from Hillary.

Trump continues observing the generosity maxim by highlighting the strength points of Hillary describing her as someone who 'does not give up', and that 'he respects that' despite the fact that he is not in complete agreement with most of her beliefs, yet, the statements positive sense weights more than that of a negative one as he grants her his approval for being a great fighter.

In addition, Trump's statements are also directly related to the point of discussion and far from being ambiguous. It indicates complaints with $\mathrm{CP}$ maxims where he clearly and truthfully expresses his thoughts by adopting short, yet meaningful utterances. This feature also supports Leech's description of Collaborative act in speaking. (Leech 1983, p.104)

In terms of the used speech acts, no implications were noticed. His statements appeared to be spontaneous and completely unprepared, since the question was unexpected for both debaters, as they usually tend to highlight each other's social, political and sometimes psychological weaknesses, and were hardly positive about each other. Nonetheless, he showed respect for Hillary's statements and performed the act of politeness directly and firmly.
2.Giving a speech to a crowd gathered in support of the United States' Law enforcement, Trump has addressed the crowd as follows.

“.... I am honored to welcome, we call this a peaceful protest, to the Whitehouse in support of the incredible men and women of law enforcement and all the people that work so well with us. And I have to tell you that our Black Community, our Hispanic Community, thank you very much"

The former US president starts his speech with a positive polite act of greeting the crowd warmly and showing appreciation for their attendance, as well as describing them 'the peaceful protest'. He then continues his support addressing the service specified in his country's law enforcements, and describes those administrations as 'incredible men and women'. This is considered showing politeness to the third party according to Leech (1983, p131), where s/he might be a part of the communication or an absent figure. The speaker tends to show respect to him/her due to his/her respect to the listener.

Trump's insistence to point out the terms 'men and women' (indicates not only his intention to show respect to the third party as mentioned previously but also to reiterate his view regarding equality between them and that he has appreciation for women as men, which is something he was often accused of not doing.

He then carries on his tactful speech by expressing gratitude to the 'Black and Hispanic communities' which are two widely spread communities in the United States in the country. The initiation to irony and solidarity, and the sense of welcoming that echoed in Trump's speech imply a generous act of politeness.

He delivered an indirect falsification for the claims of him being racist and anti-Hispanic figure. His emphasis on the Black and Hispanic community is the best evidence, especially after the false killing of George Floyd, the African-American individual, whose murdering led to the outbreak protests throughout the United States. Another issue is the wall, the victory that Trump administration is proud of, forever. Building of the wall started at the beginning of Trump's wining of presidency. It was also one of his greatest goals he mentioned in the presidential electoral campaigns. The wall was mainly, according to Trump, to protect the US by preventing illegal immigrants from Mexico to pass the US-Mexico border.

So, in this speech, Trump has indirectly initiated an act of generosity by addressing both the Black and Hispanic communities as 'our' communities. He intended to navigate the idea that, these communities are part of the American population and anything opposing those believes are nothing but allegations.

As far as the cooperative principle is concerned in this specific context, the former president's speech is truthful, since there is no evidence to prove otherwise. The speech is also implicature formation, or evidence for and implicature or plies as for the application. 
3. Donald Trump made a tweet on Sep.27th, 2020, regarding his nominee to the Supreme Court. He wrote:

"Today, it was my great honor to nominate one of our nation's most brilliant and gifted legal minds to the Supreme Court. She is a woman of unparalleled achievement, towering intellect, sterling credentials, and unyielding loyalty to the constitution: Judge Amy Coney Barrett..."

https://twitter.com/realdonaldtrump/status/1310036242470514689?s $=21$ (Tweet)

https://twitter.com/realdonaldtrump/status/1310036242470514689?s=21

(Video)

Trump started the tweet with a direct gratitude towards the judge he has chosen to join the Supreme Court. He is apparently being tactful and generous in his view of the judge and appreciative other talent and hard work.

The former president has an indirect dispatch in the tweet, though. Trump was being accused of attacking women since the early days of his campaign. People, who were not obviously in his supporting zone, were accusing him of hating women. So, this step from the former president was to prove those claims wrong, and to show them that he is supportive of powerful women and trusts them to be in charge of sensitive duties.

The tweet is short and simple, but clear, informative and truthful. He did not attempt misleading, and avoided ambiguity in terms of the content of his tweet, which was to celebrate Barrette, the judge. Therefore, it is fair to say that the writer has observed all the CP maxims, by means of being quantitative and qualitative in his short message. As well as being brief and obeying the maxim of manner, in addition to his collaborative and convivial approach to Leech's politeness principles.

4.On Dec.12th,2020, the former US president, has made a short appearance on Tweeter to announce the good news for his nation and the world. It was the accomplishment of delivering the anti Covid-19 vaccine ... he addressed the nations as follows:

"I have really good news. Today our nation has achieved a medical miracle. We have delivered a safe and effective vaccine in just nine months. This is one of the greatest scientific accomplishments in history. It will save millions of lives and soon end the pandemic once and for all ...... on behalf of the American people I'd like to thank all of the brilliant scientists, technicians, doctors and workers who made this all possible. Pfizer and Moderna have announced their vaccine is approximately $95 \%$ affective, far exceeding expectations. These vaccines are also very safe. American citizens participated in clinical trials that were far larger than normal and had no side effects... Today's achievement is a reminder of America's unlimited potential when we have the will and the courage to peruse ambitious goals ..."

https://twitter.com/realdonaldtrump/status/1337586206683574272?s=21
The former president starts his speech with a positive vibe announcing really good news (from his perspective). He addresses the nation as miracle makers, referring to the healthcare givers and appreciating their role. He continues praising the nation by granting them one of the greatest accomplishments in the history. Then he gives comfort and assurance that their life would get back to normal again, due to the amazing accomplishment their fellows have achieved and the 'it will save millions of lives' expression is an indirect message for the Democratic politicians and the people supporting them that the pandemic will end in the hands of this president unlike their constant accusation for the increase of death rates due to Covid-19 and that Trump's administration could do nothing about it.

He again shows his gratitude and appreciation to everyone who contributed to such miracle and calls them by their occupations to say that each one of them has his/her own share in this achievement, no matter if they were directly in the labs or not.

The former president then goes to using his power and influence positively (line 5,6,7), to convince people to get vaccination, and ensuring them that it is safe, referring to the confirmation from (Pfizer and Moderna the Vaccine Companies). The former president is apparently well aware of his role as president in critical times in particular, therefore he does his best to make his people believe in him and do whatever he asks as it would be the best for them.

Despite the variety in manifesting politeness, these samples have some common factors in the application of the concept. They are all to be described in terms of (Leech 1983, pp. 104105 )'s convivial illocutionary function that is an intrinsically polite illocution with a positive polite nature, including 'thanking, appreciating, showing gratitude and congratulating'. These types of illocution's are of the benefit of the hearer with no cost, and only the physical efforts to the speaker by making the statement is what considered costly for the speaker.

Then, the adaptation of truthful, short yet meaningful statements, indicate speaker's intention to cooperate in terms of (Grice 1975)'s Cooperative Principle. Since the truthfulness refers to the speaker's application of (Quality maxim), while the employment of short, but purposeful statements explains his will to employ the (Quantity maxim). The same is true for the unity and clarity of the statements which correspond to the (Relevant) and (Manner) maxims respectively.

\section{B. Approbation and Modesty Maxims}

1.Weijia Jiang is an Asian CBS reporter. She asked Donald Trump about his delayed order to close the borders to avoid the spread of COVID-19.Donald Trump answered:

"Who are you with? So, if you look at what I did in terms of cutting off or, banning China, from coming in.. Nice and easy, just relax ....we cut it off, people were amazed, these gentlemen, everybody was amazed that I did it... We were very early and, I am the president and you know what I just did ... how many cases of virus were here in 
the United States when I issued the ban? Do you know the number?... No, no, no, you have to do your research.. Keep your voice down, please, keep your voice down...And you should say thank you very much for good judgment.

Go ahead; please" (referring to another reporter to ask his/her questions)

https://www.dailymotion.com/video/x7tmyls

The former president starts his answer, by asking a direct question about the agency that the reporter works for. This seemingly implies his intention to react not in accordance to the question by means of answering it, but, as to whether or not the reporter is broadcasting from a station that the president is in good terms with, i.e. he has a premeditated attitude towards the situation, with no consideration to the question. He usually tends to react with a negative attitude towards the agencies that are not of his preference.

Then, he starts answering by 'banning China from coming in'. In addition to the ill-mannered act of directly threatening and accusing the third party, this sentence includes violation of CP's relation maxim since the speaker is not relevant to the question's topic in his statement. He focuses on placing the blame somewhere else, referring to the country where the Covid-19 has first appeared. The former president may have intentionally attacked the country, as the reporter is from Asian origin, hence he may attack an Asian country through the reporter. In both cases of intentional or unintentional act, it is an impolite one. If the threat is meant to be for China, then a third party has been treated disrespectfully. If the threat was intended to be to the reporter, it is also an obvious direct threat to her face.

Donald Trump goes on by directly praising himself and what he has done for the country and how quick he was in closing the borders. He supports his claim by referring to the amusement of people for what he has done. This is an explicit act of exaggeration of one's generosity which violates the first submaxim of Modesty and committing the social transgression of boasting Leech $(1983$, p.136).The act of exaggeration that Trump is practicing is also tedious according to (Leech 1983).So, the speaker fails to commit himself to a favourable opinion which means that he cannot (truthfully) do so, hence violating Approbation and Modesty maxims. Where he could simply avoid dispraise and causing harm to the listener by making some relevant, yet indirect statements referring to the crisis the virus caused.

The speaker attempts to embarrass the listener and implicate doubt regarding the latter's accuracy in her report preparation, when he asks her whether or not she is informed about the number of virally effected people in the US whenever he (Trump, the speaker) closed the borders, and asking her, by means of preparing the questions she wants to ask on the basis of a well-managed research. One more time the speaker fails to commit himself to a favourable opinion concerning the hearer, but rather to himself which implies that he is not obeying the Approbation maxim regulations on the account of Modesty maxim. i.e., the speaker is praising himself on the account of dispraising the hearer.

Trump has also violated the CP's Quality maxim in regards to the number of effected people at the time of issuing the ban, since many reliable sources had provided genuine reports declaring thousands of deaths on daily basis, in addition to the United States' infection and death records which hit the top compared to other countries in the world for quite some time. Donald Trump also exaggerates in claims regarding the effect of the mission he had accomplished banning the US soil borders with China, thinking that it is the best way to handle the pandemic crises. The act of exaggeration is also tedious according to Leech (1983).

Through the act of imposition, the speaker practices threat to the hearer's face when he praises himself and indirectly brings to attention the role he plays in the country by stating that he is the one who knows the best for the country'. In the end of his statement, Trump accuses the reporter of not being thankful and appreciative, but questioning his power instead. The tone of imposition beholds the refusal of showing cooperation in the communication. The threats to the hearer's face and freedom of choice are indications of another aspect which (Leech 1983, p.105) has pointed out, that is a conflictive illocution which conflicts with the social illocutions where the second party is often considered and being politely behaving.

The speaker has also violated the maxim of manner, since the sequence of his speech was not properly arranged and was often distracted. He was not related to his topic as well. He brought up topics of praising himself that were not a part of the reporter's question.

2.A briefing was held for the former US president to discuss an incident of confidential data exposition. He states:

Donald Trump; "I think it is disgraceful, disgraceful that the intelligence agencies allowed any information that turned out to be so false and fake, out. I think it is a disgrace and I say that, and that is something that Nazi Germany would have done and did do. I think it is a disgrace... They are going to suffer the consequences... and as far as CNN going out of their way to build it up ... I am not going to give you a question, you are fake news."

https://www.youtube.com/watch?v=W6ZHY0E4 Wg

At the beginning (line 1), the former president expresses his discomfort over the exposition of some classified data, with an expression of bitterness and direct accusation to the intelligence agencies that happen to be the third party, for his belief that they caused such undesirable incident. He then continues his attack, not only to the third party but to the fourth party this time when comparing the agencies act of disgrace, according to him, to that of the Nazi Germany. This is a complete violation of the first submaxims of both Approbation and Modesty maxims towards the third party. Unlike the previous speech, the speaker in this precise speech has not employed any statement of praise to himself. However, the strategy of attack and accusation for the third party is just about doing so by means of Approbation 
maxim. In any given situation where the third party is involved, the speaker should consider the third party's position in the communication, meaning that, if the third party happened to be on the speaker's side, then the speaker has the freedom to dispraise him/her/them on the account of praising the second party, which is not the case of this speech event. The second probability is that to consider the third party, the 'other', in Leech's (1983, p.131) term, where the speaker is obliged to show politeness, which again did not happen in this communication setting. So, not to praise one's self, does not necessarily imply praising the other, as this example illustrates. Before moving to address $\mathrm{CNN}$ at the end of his speech, the former president makes a promise of threat targeting the ones who are held responsible, by paying the consequences of their action. Then he finalizes his statement with a punishment to CNN by 'not taking their questions', for 'building up' the scandal as he accuses them. This is another act of dispraise to the hearer directly, which has a background of political cold war between the former president as a Republican and the Democrats-affiliated press agencies.

In terms of obeying $\mathrm{CP}$ maxims, the speaker was telling the truth (observing Quality maxim) about the disgracefulness of the act of leaking out the information. It should not happen in an administrative organization that has such a strong base and highly trusted and intelligent people. The amount of information he provided regarding the topic was also sufficient (Quantity). As well as being clear (manner) and, related to the topic (relation).

3. The context is a joint press conference between the former US president and president of Finland. A reporter asks the US president about Joe Biden, a then democratic Congressman and newly-elected US president, and his son who served in the war in Iraq in the past, and has had some health issues recently.

Trump: "Look, Biden and his son are stone-cold crooked. And you know it. His son walks out with millions of dollars. The kid knows nothing. You know it, and so do we."

Go ahead. Ask a question now.

Reporter: The question, sir, was: What did you want President Zelensky to do about Vice President Biden and his son, Hunter?

Trump: Are you talking to me?

Reporter: Yeah. It was a just a follow-up of what I just asked you, sir.

Trump: (Inaudible)finish with

me. Listen. Listen. Are you ready? We have the

President of Finland. Ask him a question.

Reporter: I have one for him. I just wanted to follow up on the one that I asked you, which was -

Trump: Did you hear me?

Reporter: What did you want him to -

Trump: Did you hear me?

Reporter: Yes, sir.

Trump: Ask him a question.

Reporter: I will, but -
Trump: I've given you a long answer. Ask this gentleman a question. Don't be rude...It's a whole hoax. And you know who's playing into the hoax? People like you and the fake news media that we have in this country. And I say, in many cases, the "corrupt media" - because you're corrupt. Much of the media in this country is not just fake, it's corrupt. And you have some very fine people, too - great journalists, great reporters. But, to a large extent, it's corrupt and it's fake. Ask the President of Finland a question, please.

Trump: You never had wins with other Presidents, did you? But we're having a lot of wins at the WTO since I became President.

https://www.whitehouse.gov/briefings-statements/remarks-president-trumppresident-niinisto-republic-finland-joint-press-conference/

The former president answers the question with a direct attack to Joe Biden and his son's face, and accuses them (especially the son) of corruption and foolishness. The nature of the communication suggests that there is no sign of violating Approbation and Modesty maxims despite the negative politeness that the speaker adopts to express his thoughts.

The second part of Trump's speech, however, has two factors that is considered impolite in reference to Leech (1983, p.139). One is to talk at the wrong time that is in Leech's term 'an interruption'. He (The speaker) constantly interrupts the reporter preventing him from completing his question in addition to not giving him a satisfactory nor a complete answer.

Trump's silence or, what tends to be an intentional attempt not to answer the reporter's question, but rather pushing him to ask Finland's president a question, is another implication of an impolite behavior according to Leech (1983, p.139).

However, he can be regarded as cooperative in Grice's terms by means of observing the Quality maxim for him being confident in his claims and the fact that he takes the audience as witnesses ensures his honesty. Keeping his statements short and informative indicates that the Quantity maxim had been observed as well. His rapid change of subjects and not being transparent enough in answering the questions (the questions he intended to skip answering) do not support the requirements of Manner and Relation maxims.

4.In a press conference that was titled as 'tense exchange' by the 'New York Times journal' later on that year, Jim Acosta, CNN anchor, confronts Donald Trump with the issue of illegal immigration to the country. Trump responds as follows:

\footnotetext{
"Here we go ... Thank you for telling me that, I appreciate it. I want them to come into the country but they have to come-in legally. You know, they have to come-in Jim, through a process... wait, wait, wait ... you know what, I think you should leave me run the country, and you run $\mathrm{CNN}$ and if you did it well, your ratings would be much better. That's enough, that's enough, that's enough... That's enough, put down the mic. I tell you what; CNN should be ashamed of itself having you working for
} 
them. You are a rude terrible person. You shouldn't be working for $\mathrm{CNN}$... when you report fake news, which CNN does a lot, you are the enemy of the people."

https://www.youtube.com/watch?v=v3abZ4aAGUU

The tension is sensed from the first sentence uttered. By stating 'here we go', the hearer gives the impression that what is coming (what the reporter has to say) is repetition and not interesting. Then, he thanks the reporter, sarcastically, for giving him the information (that he did not need apparently), and all this is not a positive beginning.

Then in saying 'wait, wait, wait' three times frequently, Trump does not ask the reporter to fall silent but, he orders him to do so. The repetition of the same word 'wait', at one time, indicates violation to the quantity maxim of the cooperative principle in addition to violating the 'Approbation and Modesty' maxims in terms of dispraising the hearer and misuse of power.

Trump again adopts the imposition attitude by saying that he is the president and he knows how to run the country the best way and that the reporter should do his job which is reporting. Then, Trump attacks the agency by accusing them of having a low rating. Trump goes on dispraising the reporter and the agency by stating that the agency should be ashamed of them to have him, which is an obvious dispraise to the reporter and his channel. He goes on humiliating both the reporter and the agency for spreading fake news, and finally accuses them of being 'the enemy of people'.

\section{Agreement and Sympathy}

1. A reporter asks the president if, he is going to continue the tense communication with them, by saying 'calling us losers to our faces and all that and, is this what is gonna be like covering you and your president? We're gonna have this kind of navigation in the press room?

Donald Trump answers as follows:

"No, Not all of you, just many of you.

Yes it is gonna be like this, David. If the press writes false stories, like they did with this .... and then we have to read probably labialized stories certainly clause, and the people know the stories are false, I am gonna continue to attack the press. Look, I find the press to be extremely dishonest; I find the political press to be unbelievably dishonest. I will say that." https://www.youtube.com/watch?v=Y2vozC_kP6Q

The term 'just many of you', relate the hearer's mind with complete disagreement. It seems that it is a premeditated attitude. Showing no signs of agreement means no sympathy as well, since observing one maxim determines the other. Trump repeats his determination of not coping with most of the press, so he is determined not to agree. He excuses his attitude with the usual accusation to the press that they are dishonest. Then he directly threatens them to their faces by saying that he will continue attacking them, which are a blatant empathy, conflictive attitude and complete disagreement. He ends his speech with a strong accusation of the press for being dishonest, not once but twice.

2. "TRUMP: "Unfortunately, much of the media in Washington, D.C., along with New York, Los Angeles in particular, speaks not for the people, but for the special interests and for those profiting off a very, very obviously broken system. The press has become so dishonest that if we don't talk about, we are doing a tremendous disservice to the American people... you know, fake news, fabricated deal, to try and make up for the loss of the Democrats and the press plays right into it... this is fake news put out by the media. The real news is the fact that people, probably from the Obama administration because they're there, because we have our new people going in place, right now.

... There's nobody I have more respect for -- well, maybe a little bit but the reporters, good reporters. It's very important to me and especially in this position. It's very important. I don't mind bad stories. I can handle a bad story better than anybody as long as it's true and, you know, over a course of time, I'll make mistakes and you'll write badly and I'm OK with that. But I'm not OK when it is fake. I mean, I watch CNN, it's so much anger and hatred and just the hatred... have a lower approval rate than Congress. Again, I don't mind bad stories when it's true but we have an administration where the Democrats are making it very difficult."

https://edition.cnn.com/2017/02/16/politics/donald-trump-news-conferencetranscript/index.html

The former president starts his statement with an unreal expression of sadness towards the press's continued publication of fake news (about him, allegedly). By playing with words, Trump tends to manipulate the mind of his audience. He makes use of people by showing that he is saving them from all the fakeness that the news spreads about him and that he is there to tell them the truth.

He then attacks a number of newspapers and agencies by names accusing them of faking the news because they are supporting the Democrats or from the Obama administration, where according to Trump, they all are conspiring against him because he is a successful president.

To follow it with an implication of solidarity in case they were publishing even bad news but not fake, he finalizes his speech with another direct threat to CNN but this time comparing it (negatively) to the Congress in terms of low rating. It is indeed an indirect attack to the Democrats since they have their members in congress higher than the Republicans that Trump represents. Also a seemingly link of CNN to the Congress which explains his constant attack in different occasions. 
3. on Dec. 24th, 2020, Trump made a tweet targeting Iran. The tweet was:

\section{"Some friendly health advice to Iran: If one American is killed, I will hold Iran responsible. Think it over"}

The speaker (writer) starts with a direct threat to the hearer (reader)'s face in a seemingly friendly statement. It is indeed an indirect threat to the hearer by means of, we are not friends and I am warning you. The second part of the statement is a direct warning that will have absolute consequences which is explicitly apparent when the speaker shows his power and greatly imposes it on the hearer. Ending the tweet with a threeword imperative utterance forms an indirect threat and warning to the hearer, and an indirect solidarity and protection for his own people.

No signs of agreement and sympathy observed in the speech towards the hearer. The speaker uses conflictive approach since he adopts indirect threats and pre accusation to the hearer to put him in the suspect zone in case of any inconvenience in the future. He could have simply stated that, in case of any involvement of the hearer proved, and then 'we' instead of ' $I$ ' will make them pay for it. Using the pronoun 'I' diminishes the other party in communication, and yields an impression that the speaker makes decisions solely and refuses to collaborate with experts surrounding him as part of his job, and rejects negotiation fall silent $s$ with other countries which explains his violation of the maxims of agreement and sympathy.

4. On Jan. $17^{\text {th }}, 2021$, CNN has announced the result of a poll held by them earlier issuing the Trump administration popularity. The tweet included the following:

"President Trump will leave office with the lowest approval rating of his presidency, with more Americans than ever in support of removing him from office, according to a new CNN poll."

Trump's popularity has drastically decreased as his final days approached in the office in 2021, especially after breaking into the Building of Congress by his supporters in a protest against the elections results earlier 2020. In addition to many unwise decisions regarding critical circumstances, the COVID-19 pandemic on top of the list where many people lost their lives as a result of Trump's unwillingness to cooperate with health professionals to save the nation as he believed that the whole pandemic is a scenario run by his enemies to turn him down. Besides, a large number of congress members from his own party had turned their back to him and voted for his second impeachment. All these are clear signs of most people's disagreement with the former president, and they had shown no empathy when it came to choose to trust another figure to run their country and the figure was from the opposite party, the Democrats, and who Trump was in obvious and public disagreement.

\section{CONCLUSIONS}

Despite the diversity in considering certain a certain act or speech event as 'polite', and the variety in strategies and to perform techniques to perform an act of politeness, being polite remains the main target of interlocutors.

The paper concludes that Donald Trump utilized direct speech acts in his tweets and press conferences, which obliged him to violate Leech's Politeness Principle and Maxims, and implicitly postulated that the violations do not contradict with cultural politeness.

However, there is no certain behavior which determines politeness at all times and there is no common method that is applicable the same way in different cultures, i.e. not every polite act has the same effect in different circumstances. Therefore, not all indirect acts are considered polite. The more direct the politer, could be postulated along with the more indirect the politer strategy.

In Donald Trump's case, despite his adaptation for a variety of strategies to deliver massages, the intention he has is often explicit. Although in political domain, the indirect strategies tend to be more favorable to keep popularity and avoid the cost of directness, for Donald Trump direct speech means honesty and frankness, and they are not expected to contradict with politeness as a principle and cultural requirement.

So, it is not the matter of classifying one speech act to be linked to a certain performance. Direct speech acts can be used collaboratively and coercively to give thanks, show appreciation, greet and assert as well as for conflictive purposes such as in cases of accusing, threatening, and cursing the others. The same applies to indirect speech acts, where the speaker can be indirectly polite by using the negative politeness strategies, as well as being indirectly impolite in cases of being sarcastic, dispraising the others, and interrupting. Hence, the paper's hypothesis is verified, which postulates that politeness could be observed using either direct or indirect speech acts.

\section{REFERENCES}

Al Juwaid, W. (2019). The Pragmatic of cogent argumentation in British and American political debates. Cambridge Scholar Publishing.

Black, E. (2006). Pragmatic stylistics. Edinburg university Press: Edinburg

Bonvillian, N. (1993). Language, culture, and communication. PrenticeHall,Inc. New Jersey. USA

Chapman, S. (2011). Pragmatics. Palgrave Macmillan.

Crystal, D. (2003). A dictionary of Linguistics \& Phonetics. 5th ed. Blackwell publishing.

Down, A., Wichmann, A. (2012). Pragmatics: An advanced resource book for students. Routledge.

Gingrich (2017). NEWT GINGRICH, Understanding Trump. Center Street. New York.

Herk, G. (2012). What is Sociolinguistics? Willey Blackwell.

Holmes, J. (2013). An introduction to Sociolinguistics. 4th ed. Pearson.

Kachru, Y. and Smith, L. (2008).Cultures, Contexts, and world Englishes.1st ed. Routledge.

Leech, J. (1983). Principles of Pragmatics. Longman. New York.

Levinson, Stephen C. (1983). Pragmatics. Cambridge University Press.

LoCastro, V. (2012). Pragmatics for language educators. Routledge.

Mahmood, R. K. (2016). Pragmatics between Microlinguistic and Macrolinguistic Levels of analysis, Global Journal of Foreign Language Teaching, Vol 06, Issue 3, (126-129). 
Saeed, J. (2009). Semantics.3rd ed. Wiley-Blackwell.

Taguchi, N. (2019). The Routledge Handbook of Second Language Acquisition and Pragmatics. Routledge.

Thomas, J. (1995). Meaning in interaction: an introduction to Pragmatics. Routledge.

Trump, D. J.[@ realdonaldtrump]. (2020, October, 10). [Tweet]. Tweeter. https://twitter.com/realdonaldtrump/status/1310036242470514689?s=21

Trump, D. J. [@ $@$ realdonaldtrump]. (2020, April, 27). [Tweet]. Tweeter.https://twitter.com/realdonaldtrump/status/1310036242 470514689 ? $=21$

Trump, D. J. [@ realdonaldtrump]. (2020, December, 12). [Tweet]. Tweeter.https://twitter.com/realdonaldtrump/status/1337586206 $683574272 ? \mathrm{~s}=21$

(2017, February, 17).Full transcript: President Donald Trump's news conference. CNN Politics. https://edition.cnn.com/2017/02/16/politics/donald-trump-newsconference-transcript/index.html

Trump D. J. [@ realdonaldtrump]. (2020, December 24). [Tweeter]. Tweeter. https://twitter.com/realdonaldtrump/status/13100362424705146 $89 ? \mathrm{~s}=21$

Trump D. J. [@realdonaldtrump]. (2021, January,17). [Tweeter]. Tweeter. https://twitter.com/realdonaldtrump/status/13100362424705146 $89 ? \mathrm{~s}=21$

Vanity Fair. (2016, October 10). Hillary Clinton and Donald Trump Say Something Nice About Each Other.https://www.vanityfair.com/video/watch/hillary-clintonand-donald-trump-say-something-nice-about-each-other
Verschueren, J. (2003). Understanding Pragmatics. Arnold. Great Britain. $\begin{array}{llll}\text { White House. (n. } & \text { d.). Retrieved from. }\end{array}$ https://www.whitehouse.gov/people/donald-j-trump/

$\begin{array}{llll}\text { White House. (n. } & \text { d.). Retrieved }\end{array}$ https://www.whitehouse.gov/briefings-statements/remarkspresident-trump-president-niinisto-republic-finland-joint-pressconference/ (accessed: September 2020).

Yule, G. (1996). Pragmatics. Oxford University Press.

(2020, April 27). Trump berates female reporter when questioned over $\begin{array}{lll}\text { Covid-19 } & \text { response. } & \text { [Video]. }\end{array}$ https://www.dailymotion.com/video/x7tmyls

(2018, November 7). 'You are a rude, terrible person': Trump attacks CNN reporter. [Video] YouTube. https://www.youtube.com/watch?v=v3abZ4aAGUU

(2016, May 31).Donald Trump attacks the press. [Video]. YouTube. https://www.youtube.com/watch?v=Y2vozC_kP6Q (accessed: December 2020)

(2016, October 10). Hillary Clinton and Donald Trump Say Something Nice About Each Other. [Video]. YouTube. https://www.vanityfair.com/video/watch/hillary-clinton-anddonald-trump-say-something-nice-about-each-other

(2017, January 11). Donald Trump shuts down CNN reporter-BBC News. [Video].

YouTube. 